\title{
KÜLTÜREL DEĞERLERİN MİKRO DÜNYASI OLARAK SANDIK İMAJI
}

\author{
THE IMAGE OF CHESTS AS THE MICROWORLD OF CULTURAL VALUES
}

\section{Ramilya YARULLINA YILDIRIM*}

ÖZ: En eski dönemlerden bugüne kadar pek çok kültürde halkın günlük yaşamında önemli yer tutan sandıklar, her dönemde ve kültürel ortamda kendine özgü içerik almasına rağmen, yapısal olarak ana vazifesini kaybetmez. Calıșmada geçmișten günümüze kadar sandığın halk kültüründeki yeri hakkında kısaca bilgilendirilir; Çă̆daș Tatar ve Bașkurt hikâyeleri örneğinde betimleme, yorum ve mukayese yöntemleri aracıyla sandığın fonksiyonel özelliği açıklanır.

Geleneksel kültürü koruyarak, günümüzdeki yozlaşmaya karşı durabilme konusunu ele alan ve bu süreçte sandık imajına önemli anlam yükleyen komşu sanatçlların yaratıcılığında pek çok ortak özellik göze çarpar. Edebi eserlerde sandık, milli kültür öğelerini taşıyan sözcük, belli bir kültürün kodu olarak sunulur. Yazarı sandığın biçiminden ziyade, onun koruyucu özelliği, milli kültürün izlerini yansıtan içeriği ilgilendirir. Bir taraftan sandık, milli ve dini gelenekleri içine toplayan, onları koruyan bir mikro dünya; diğer taraftan ana kahramanın gençliğinin en güzel umutlarını ve değerli hatıralarını kendisinde barındıran bir hatıra kutusudur. Aynı zamanda somut gibi kabul edilen sandık, yaşlılar için geçmişin ve soyut düşüncelerinin, manevi değerlerinin şahidi olan canlı bir nesnedir.

Eskimiş, yıpranmış sandıklar her yaşlı için geçmiş dönemin yeni zaman koşullarında da devam edebilmesine destek olan en değerli eșyadır. "Usta ve Çırak" hikâyesi hariç, yazarlar kültürü ve milli değerleri koruyan ve gelecek kuşağa aktaranlar olarak nineleri görür, onları Milletin Anası olarak simge seviyesinde tasvir ederler. Halk kültürünü yansıtan bu tür eserler kültürdilbilim açısından incelemeler için de zengin kaynak içerir.

Anahtar Kelimeler: Tatar edebiyatı, Başkurt edebiyatı, milli değerler, sandık.

ABSTRACT: Chests, which have had a significant place in the daily lives of people in several cultures from the past to the present, do not lose their main structural function although they have contained unique contents in all periods and cultural settings. This study provides brief information about the place of chests in fold culture from the past to the present and explains the functional characteristics of chests in the case of Tatar and Bashkir stories.

Several common features may be observed in the creativity of Tatar and Bashkir artists who deal with the topic of standing against corruption today by preserving the culture of the past and attribute a significant meaning to the image of chests in this process. In literary works, a chest is presented as a word that carries elements of the national culture, a code of a certain culture. The author is concerned with the protective function of a chest and its contents that reflect the traces the national culture, rather than its form. A chest is a microworld that collects national and religious traditions in it and protects them, a box of memory that harbors the most beautiful hopes and valuable memories of the main character; a chest that is assumed to be tangible is, for the elderly, is a living object that is a witness of the past and their abstract thoughts, spiritual values.

\footnotetext{
* Prof. Dr. - İnönü Üniversitesi Fen-Edebiyat Fakültesi Türk Dili ve Edebiyatı Bölümü/Malatya

- ramilya.yildirim@inonu.edu.tr 
Antiquated, worn out chests are the most valuable thing that supports the continuation of the past ear in the conditions of the new era for every elderly person. Except for the tale of "master and apprentice", authors see grandmothers as those who preserve culture and national values and transfer these to future generations and describe them on the level of a symbol as the Mothers of the Nation. Such works that reflect folk culture are also a rich source for studies in the field of ethnolinguistics.

Keywords: Tatar literature, Bashkir literature, national values, chest.

\section{Günlük Hayatta Sandık}

Pek çok Türk dillerinde rastlanılan sandık sözünün, köken bakımından Arapça bir söz olup, Rus diline de Türk dillerinden geçtiği bilinmektedir. Codex Cumanicus'ta (XIV. yy. başı) günümüz Tatar Türkçesinde kullanıldığı şekilde sandık olarak yer almıştır (Milliyet Sözlüğü, 2007: 394). N. M. Shanskiy'in Rus dilinin online etimoloji sözlüğünde sandık sözü "Yunanca "syndokeion"dan Araplar aracıllğıyla Türk dillerine ve Türkçeden Rusçaya XV. yy. öncesi geçen alıntı bir kelime" olarak açıklanır (URL-1).

Sandıklar geçmişten günümüze kadar pek çok kültürde halkın günlük yaşamında önemli yer tutar. Eski Mısır ve Antik Yunan uygarlığı döneminde halkın yaşam tarzının önemli ve popüler parçası sayılan sandıklar, ilk dönemlerde giyim, kitap ve değerli eşyaları koruma için kullanılan günümüzdeki dolap vazifesini üstlenen mobilya olarak görev yapar. İslam dininin kabulüyle sandık kelimesi, Rusya'da hayat sürdüren Türkler arasında kullanılmaya başlanır ve bu söz Ruslar arasında da yaygınlaşır. Diğer taraftan, Rusların Avrupa'ya açılması ve siyasi ticari ilişkilerin başlatılması sonucunda, Avrupa gelenekleri Rus ustaları tarafından kendi kültürlerine aktarılmaya ve sandıklar Rusya Türklerinin yaşamında da yer almaya başlar. Sandıklar Orta çağlarda çok amaçlı kullanılır: uzak yolculukta alış veriş yapan tüccarların vazgeçilmez eşyası, yol çantası olur; bir mobilya olarak, evin içinde bazen masa, sandalye veya üzeri örtülüp yatak vazifesini de görür. Ormanlarla iç içe yaşayan Rusya Türklerinin köy evleri ve hamamları, bildiğimiz üzere son yirmi yıla kadar ağaçtan yapılırdı ve özellikle kurak yaz aylarında yangın olasılığı da çok yüksek olmuştur. En değerli eşyaları içinde barındıran sandık, bu tür felaketlerde ilk olarak kurtarılırdı (URL-2).

Her evde bulunan ve ev sahibinin maddi durumuna göre sayısına, kalitesine ve yapı özelliği bakımından değişen sandıklar, zamanla aksesuar olarak evin bir köşesinde saklanmıştır. Günümüzde yaşlıların evinde bulunan eskimiş sandıklarda geçmişten gelen aile değerleri ile ölümlük eşyaları korunur; çeşitli desenlerle süslenip yapılan sandıklar ise, genç kızların mutlu bir evlilik hayatı umuduyla özenle hazırlanan çeyiz ürünlerini içine alan bir mekândır. Hulasa, sandık her dönemde yapısal (biçim) olarak değişmez, fakat her kültür ortamında kendine özgü zengin bir içerik alır.

\section{Halk Kültüründe Sandık}


Eğitime önem veren Tatar Türklerinde şakirt sandığı kavramı da bilinir. Toprağından uzaklara eğitim almak için ünlü medreselere giden gençlere ait olan sandıkta, daha çok eğitim araç ve gereçleri ile birlikte annesinin evden gönderdiği özel eşyalar da korunur. Medreseden mezun olduktan sonra pek çoğu, Kazak bozkırlarında hayat sürdüren Türklere eğitim vermeye gittiklerinde yanlarında o sandıklarını da taşır.

Çok eskiden itibaren günümüze kadar sandık, gelinlerin atributü sayılır. Evlenme çağına gelen Tatar kızları arkadaşlarıyla birlikte avlak evlerde* akşam oturmalarında çeşitli el işlemeleri yaparak kendi emeğiyle kendi çeyizini hazırlar. Yeni gelinin çalışkanlığı ve hamaratı sandıktaki ürünlerine göre değerlendirilir. "Kızın birne dedikleri çeyizi, kalay sandık diye adlandırılan ak pirinç sandığa toplanır ve baba evinden bu sandıkla götürülür." (Zaripova Çetin, 2016: 53). Güvey evi gelinin çeyiz sandığında bulunan eşyalarla süslenir ve bu ev giydirme, sandık açma geleneğinde yakın kız arkadaşları katılır.

Günümüzde Tataristan'ın bazı bölgelerinde sandık, gelin çeyizinde mutlaka bulunması gereken önemli eşyalarındandır. Tatar Türklerinin yaşadığı çeşitli bölgelerde, gelin sandığıyla ilgili çeşitli gelenekler mevcuttur. Örneğin; Balık Bistesi ilçesinde gelini baba evinden alırken, gelinden önce damadın arkadaşları tarafından evden sandık çıkarılır, bazı köylerde ise o sandığın üzerine gelin de oturtulur (Zakirova, 2019).

Sandık yapımında desenlerle birlikte renk seçimine de önem verilir. Eski Türklerde kutsal sayılan renklerden yeşil ve mavi renkler Tatarlar tarafından en çok tercih edilen renkler olmuştur. "Demir bezeklerle süslenen çeyiz sandıkları, hala Kazan'ın kuzeyindeki Baltaç ilçesinde özel ustalar tarafından yapılmaktadır." (Zaripova Çetin, 2009: 111).

\section{Halk Edebiyatında Sandık İmajı}

Sandık imajı pek çok kültürün mit, masal, destan, mani, deyim ve atasözleri gibi türlerinde karşımıza çıkmaktadır. Tatar halk edebiyatı uzmanı Fatih Urmançe'nin araștırmalarına göre, uluslararası mitlerde, masal, kitabi ve folklar destanlarında daha çok sandıktaki çocuk motifi yaygındır. Eski Mısır mitlerinde ana kahraman sandığa koyulup nehre atılır; Avesta kitabında, Tevrat'ta ve Kuran'da da aynı motif işlenir. Daha çok ana kahramandan kurtulma yolu olarak kullanılan sandık, daha sonra yazılı edebiyata da geçer. Örneğin; Firdevs'inin "Şehname"sinde Huma, dünyaya yeni gelen Darab adındaki oğluna tahtı vermemek için, çocuğu sandığa koyup, akarsuya atar. "Tahir ve Zühre" adlı Tatar-Türk destanında, Başkurt Türklerinin "Dokuz Oğlan", "Padişahın Üç Karısı" gibi masallarda, "Han ve Akıllı Vezir", "Cesur Ada" adlı Kazak masallarında benzer motif karşımıza çıkar (Urmançe, 2009: 319-320). Tatar atasözlerinden "Açtırma sandıknı, kürsetĕrsĕn kaldıknı" (Açtırma sandığı, gösterirsin kaldı̆̆ı), "Bĕrevnĕn de

\footnotetext{
* Büyüklerin evde olmadığı zaman gençlerin bir araya toplandığı ev.
} 
sandığı buş tügĕl” (Hiç kimsenin sandığı boş değildir), "Biklĕ sandıkta cevher yatır" (Kilitli sandıkta cevher yatmaktadır) (İsenbet, 2010: 413) gibileri halkımız arasında yaygın olup, daha çok insanın iç dünyasını, kişiliğini yansitirlar.

Antik Yunan uygarlığına ait yaratılış efsanesine göre, ilk kadın olarak yaratılan Pandora'ya Tanrılar tarafından hediye edilen kutunun açılmasıyla, çeşitli kötülüklerin dişarıya dağılmasından sonra tek bir umudun içinde kalması, kadın elindeki kutuya derin bir anlam yüklemektedir. Zira günlük hayatta kutu ve sandık daha çok kadınlarla bağlantılı, hem soyut hem somut anlamda onların umut ve düşünceleriyle bağdaştırılır.

\section{Çağdaş Kazan Tatar ve Başkurt Edebiyatlarında Sandık İmajı}

Tatar edebiyatında sandık imajı realist edebiyat diye adlandırılan, halk kültürünü ve onun gerçek yaşantısını yansıtmada ve canlı konuşma dilini kullanmada ilk adımlarını atan XX. yüzyıl başı (1901-1917) eserlerinde karşımıza çıkar. Halkın yaşam tarzına ve milletin etnografik özelliklerine önem veren eğilim, edebi eserlerin sanatsal yönden gelişmesine, tasvir teknikleri bakımından zenginleşmesine neden olur. Bu devirde özellikle Ayaz İshaki, Alimcan İbrahimov, Mirheyder Feyzi, Aliasker Kamal vs. gibi sanatçlar tarafından Tatar halkının yaşam ve düşünce biçimini, milli gelenek göreneklerini merkeze alan eserler yazılır. 0 eserlerde, örneğin; geçiş dönemi geleneklerinden düğüne hazırlık ve gelin çeyizi gibi geleneksel olay çizgilerinde sandık, genç kızların geleceğe yönelik güzel duygularla hazırlanmış el işlemelerini kendi içine alan bir umut sandığı, diğer taraftan da gelin evinin önemli bir aksesuarı olarak sunulur.

Fakat Sovyet ideolojisinin hâkim olduğu dönemde eskiye özlem göstergesi olarak yasaklanan milli motifler, bir süreliğine sandığa kapatılmıştı. Pek çok sanatçının bilinçaltı sandığında korunan milli değerler 1970’li yıllara doğru ancak gün ışığına kavuştu. Bu konuda Tatar halkının yaşam tarzını, gelenek-göreneklerini ve hemşerilerinin becerilerini ustaca kaleme alan Ömer Beşirov (Doğduğum Yer, Yeşil Beşik) ve Muhammet Mehdiyev (Turnaların İndiği Yerde) öncülük eder. Zamanın değişmesi değerlerin de değişimine yol açtığından dolayı, halkın günlük hayatındaki sandığın da değeri, vazifesi değişime uğrar. Sandık, güçlü kültürlerin etkisinde kaybolmaya ve unutulmaya yüz tutan milli değerleri koruma mekânına dönüşür. Yetmişli yıllardan sonra yazılan eserlerin pek çoğunda sandık imajı, kendi geleneklerine ve tarihine bağlı olan yaşlı kahramanın ayrılmaz hatıra sandığı vazifesinde, geçmiş ile bugünü ve geleceği bir birine bağlayan halka olarak kullanılır. Nesir türünde sandık her zaman ana kahramanın geçmişle ilgili duygularını ve hatıralarını kendisinde koruyan bir mikro dünya olarak ele alınır. Sandık, nesilden nesle, kuşaktan kuşağa aktarılması gereken değerler dünyasına dönüşür. Aynı zamanda sandık, yaşlıların ebedi hayata geçiş için hazırlanan ölümlük eşyalarını da içerir. Kuşaklar arasındaki bağların kopması ve yozlaşma gibi güncel konuları ele alan Tatar ve Başkurt yazarlarının eserleri örneğinde mevcut düşünceler 
kanıtlanmış olur. Çalışmamızın merkezi kavramı olan sandığın ilk anlamı ötesindeki kültürel anlamını açıklama üzerinde durulacak, sandığın hangi biçimde olduğundan ziyade, onun içeriği ilgi odağı olacaktır.

Tarihi geçmişte Altın Ordu, daha sonra Kazan Hanlığı gibi bağımsız devletlerin sinırları içinde yaşayan, aynı su ve topraklardan beslenen Tatar ve Başkurt Türklerinin, bildiğimiz üzere pek çok sözlü ve edebi mirası ortaktır. 1917 Ekim ihtilaline kadar mektep ve medreselerde verilen eğitim dili ortak, yazarlarımız müşterekti. Kazan Hanlığı Ruslar tarafından işgal edildikten sonra doğuya göç etmek zorunda kalan Tatarları, Başkurt toprakları kendi kucağına alır ve burada çok sayıda yetenekli Tatar sanatçı yetişir. Onlardan en ünlüsü, mirza soyundan gelen ve "eserlerinde insan psikolojisinin derinliklerini, çaresizliğini, umutlarını ve umutsuzluklarını çok iyi bir şekilde yansıtabilen Tatar edebiyatının önemli kilometre taşlarından birisi" (Kamalieva, 2013: 1784) Emirhan Yeniki'dir.

Başkurdistan topraklarında doğup büyüyen ve Başkurt Türklerinin gelenek-göreneklerini iyi bilen Tatar yazarı Emirhan Yeniki'nin (19092000) "Eytĕlmegen Vasıyĕt" (Vasiyet, 1965) adlı uzun hikâyesinde kuşaklar arasındaki kopma problemi yaşlı bir Başkurt ninesinin hüzün dolu öyküsü üzerinden anlatılır. Eserden anlaşıldığına göre, hayatın zorlukları içinde kocası ile birlikte topluma eğitimli, başarılı çocuklar yetiştiren ve Yolkutlu köyünde yalnız yaşam geçiren nine bir gün hastalanır. Şehirde yaşayan çocukları nineyi tedavi için şehre getirir, farklı şehirlerde yaşayan tüm çocukları yanına toplanır, annelerine iyi bakar. Nine birkaç kez vasiyetini anlatmaya çalışır, fakat çocukları bunu önemsemez, ninenin son vasiyetini dinlemeye zaman ayıramaz. Aslında nine en değerli eşyası, sandığı hakkında bahsetmek ister. Köyündeki sandıkta Başkurt kızlarının çeyizinde bulunan, kendisinin gençlik yıllarının hatırası, merhum eşine ait olan ve kuşaktan kuşağa aktarıla gelen milli giysiler bulunmaktadır. Bu yadigârları korumayı ve nesilden nesle aktarmayı, nine kendisinin vazifesi olarak görür.

Hikâyeden anlaşıldığına göre, Aknine'nin gerçek adı bile unutulmuş, zira güzelliğinden ve temizliğinden dolayı köy halkı, onun yaş özelliklerine göre Aksılu (Ak güzel), Akgelin, Akyenge ve yaşlandığında Aknine, demiş. O, "hayatın çelişkili yollarını geçen tecrübeli, halkının - Başkurt Türklerinin zekâsını sindiren, ülkeye iyi uzmanlar doğurup yetiştiren, sosyal kazançların büyüklüğünü göre ve anlayabilen ve candan gönülden gururlanıp yaşayan kocaman yürekli bir anadır." (Zaripova Çetin, 2019: 705). Aknine, tüm annelerin merhametini, büyüklügünü ve fedakârlığını kendisine toplayan, kendi toprağına, diline, örf ve adetlerine bağlı olan, onları kuşaktan kuşağa aktarmaya çabalayan Vatan ana simgesidir.

Sahibinin yaşıtı olan sandığın diş görünüşü hakkında çok kısa belirtilen cümle uzun bir ömrü göz önünde canlandırır: "Eski yeşil sandığı... herkese tanıdık sandık. Çocukları onun üstünde oyuncaklarıyla oynamıştı..." (Yeniki, 2012: 82). Sandığın içeriğinde Başkurt ninenin değerli yadigârlarını tanıtırken, yazar onları ninenin duygularına sararak, detaylı tasvirler 
kullanır. Bu tasvirlere yazarın sanatsal milli dünya görüşü de yansır. Örneğin; "Çok kıymetli bazı şeylerini çocuklarına isim isim bırakmak istiyordu. Ne satmaları, ne de tutup başkalarına vermeleri için değil; sadece ondan bir hatıra olarak saklamaları için bırakmak istiyordu. Mesela; sırmalı, yakut kopçalı sarı kadife cepkenini Gülbikesine, küçük mercan işlemeli rengârenk ipek astarlı fesiyle tokasını Perm'deki büyük kızı Sılubikesine, kocasından kalan su samuru derisinden yapılmış kalpağı, oğlu Sufiyan'a ayırmıştır. Bir de çok eski akçeler ve çeşitli renkte taşlarla bezenmiş gerdanlığı vardı. Kabul ederse bunu, Rus gelinine hediye etmek istiyordu. ...onları sadece kendi anneleri değil, onun gibi birçok Başkurt kızı, Başkurt gelini de takardı. Sadece bunun için bile onlar bu elbiseleri bir şekilde saklamalıydılar. Yoksa her şey yok olup gidiyor, unutuluyor..." (Yeniki, 2012: 86). Bunların dışında sandıkta bilezik, gerdanlık, gümüş pullarla yapılmış saç örgü süsü, "kızken kendi elleriyle işlediği kırmızı oyalı havluları", "babalarının, gençken elinde gezdirdiği kısa saplı, deri püsküllü, üç örgülü, her örgünün ucuna gümüş levha geçirilmiş harika bir kamçısı" vardı. Evet, nine son vasiyetinde çocuklarına bu değerli eşyaları verecek, geçmişlerine ve kendi topraklarına bağlılıklarını sağlayacak, milli benliklerini unutmamalarını isteyecekti. Diğer taraftan, sandıkta bulunan beyaz kefenliğini kendisini son yolculuğa uğurlarken kullanmalarını söyleyecekti. Böylece Aknine sandığının boşalması gerekirdi, fakat yaşlı ninenin son vasiyetini dinlemeye zaman ayıramayan çocukları, sandığı ve sandık içinde bulunan yadigârları tiyatro müzesine gönderir. Böylece vasiyet yerine getirilemez...

Aknine ile sandık bir bütündür; ikisi de milli hafızanın sembolleridir. Aknine, hanımlara ait olan tüm güzel sıfatları, milli karakter özelliklerini kendisinde barındıran ve koruyan bir canlı varlıktır. Sandık ise Başkurt Türklerinin milli ve dini geleneklerini içine toplayan, onları koruyan bir milli mikro dünya; diğer taraftan Aknine için gençliğinin en güzel umutlarını ve değerli hatıralarını kendisinde barındıran bir hatıra kutusudur. Somut gibi kabul edilen sandık, Aknine için geçmişin ve soyut düşüncelerinin, manevi değerlerinin şahidi olan canlı bir nesnedir.

Başka bir Kazan Tatar yazarı Flüs Latıyfi'nin (1943-2010) "Kömĕş Bĕlezĕk" (Gümüş Bilezik) adlı hikâyesinde yer alan sandık, dış görüntü olarak daha ayrıntılı tasvir edilmiştir. Bu tasvirler üzerinden Tatar Türklerinin renk seçimi (Sandıklarda daha çok doğayı ve yaşamı yansıtan yeşil renk tercih edilir), işlemelerdeki zevki ve maddi durumu anlaşılır: "Köşelerine pirinç kalay vurulmuş, yanlarına ve kapağına kalay bezekler işlenmiş yeşil sandıktı. Pirinçleri solup gittiği, boyası çıkan yerlerde parçalanan tahta, yılların geçmişiyle kararmış, kayın kömürü görüntüsüne girmiş... Torunlarına dahi ulaşır o, sandal ağacından yapılmış" (Latıyfi, 2001: 411). Ana kahramanın hatıralarında sandığın tarihçesi de canlanır: "Ne zamandır babasının birilerine bu sandık hakkında söylediğini, kısmen aklında kalan sözleri hatırladı Cihan. Onun hoş kokusu yüz yıl sonra bile 
geçmezmiş. Çin ülkesinden, Hindistan civarından gelmiş değerli ağaçmış o." (Latıyfi, 2001: 411).

Emirhan Yeniki'nin "Vasiyet" hikâyesine benzer bir şekilde, Flüs Latıyfi de sandığın içeriğini insan duyguların merkezi ile bağlantıda verir. 20 yıl önce hazırlanan ölümlükleri kendisinde barındıran sandık, aynı zamanda ebedi dünyaya göç etmeye hazırlanan Cihan teyzenin kültürel geçmişini de muhafaza eder. "Dıştan paslanmış gibi görünen sandığın içi sapsarı parlayarak ışıldıyor" ş̧eklindeki tasvir, görüntü olarak yaşlanan fakat iç dünyası temiz ve aydın olan eser kahramanıyla bir paralel oluşturur. Yazar geriye dönüş ve bilinç akımı tekniği yardımıyla, sandıkta bulunan ve Tatar kimliğinin göstergesi olan değerli yadigârlar ile tanıştırırken, Cihan teyzenin de kişiliğini ortaya koymaya başlar. Eskimiş sandıkta saklanan, geçmişin izlerini taşıyan eşyalar ne kadar değerliyse, ana kahramanın gönül sandığı da o kadar güzel hatıralar ve geleceğe yönelik umutlarla doludur. Örneğin; "Cihan, sandık içini karıştırıyor. Ne toplamış, ne gizlemiş? Kendisi giderse, aslını saklamak için çocuklarına, torunlarına ne kalır?.. Sandıkta gençlik hatıraları, kızlık çağının değerli yadigârları da duruyor... Simler, altınlı göğüslük, gerdan zinciri... Nesilden nesle geçen aile yadigârları. Cihan'ın soyundan kaç kız onları şıkırdatıp damat evine gitmiş ve değer verip sandıkta saklamış!.. Cihan bohçayı çözdü ve bir an donup kaldı. Çoktan unutulmuş bilekliğin üzerinde idi onun bakışı. Başlarına aslan sureti yapılmış, ortasına gök renkli büyük firuze taşı koyulmuş, yılların geçmesiyle çok aşınmış, gümüş bezemeleri yok olmuş, önemli ve değerli olan bu ziynet, şimdi ataların mirası, kaynanam hatırası diye saklanmış, göze fazla çarpmayan bir eşya idi. İște bugün... bu bilezikten gelen ışık gözlerini kamaştırdı Allah'ım!.." (Latıyfi, 2001: 411).

Sandık içindeki en değerli yadigârlardan sayılan ve sıcak nur akan tılsımlı bilezik, ana öğelerden sayılır ve kendisi nesilden nesle aktarılması gereken değerlerinin simgesel temsilcisi olarak kabul edilir. Başkurt Aknine gibi, yalnız hayat sürdüren Cihan'ın da ölmeden önce çocuklarına aktarması gereken yegâne dileği vardır: "Ey Allah'ım, tek dileğim var: eşim Devletimin neslinden olan çocuklarım ile vedalaşayım ve bu hikmeti onlara söyleyeyim. Sağ iken dönüp görsünler" diyerek bileziği yaralı elleri ile ovalayarak söylendi... Sıradan bir bilezik değil... Hikmetli, Üç hikmeti... Her neslin üç dileğini gerçekleștirebiliyormuş... Sadece atadan kalan bir mal, mülk değil, aynı zamanda senin dünyada nasıl yaşayacağını, nereden gelip nereye gittiğini açılkayan büyük bir yadigâr bu. Yadigârsız kişi fakir olur, serseri olarak yaşar, serseri olarak ölür. Kararmış gümüșe batan eski harfler bunu söylemeye çalışmiyor mu?

Bu nezimnĕy kedrĕnĕ ahmak bĕlmes.

Gakil kěşĕ tınlar, aylar, bĕlĕr imdi

(Bu şiirin kadrini ahmak bilmez,

Akıllı kişi dinler, anlar, bilir şimdi), diye boşuna yazılmamıştır." (Latıyfi, 2001: 413-415). 
Sandal ağacından işlenen sandık, sandığın içindeki tılsımlı gümüş bilezik ve onların değerini anlayan yaşlı anne gibi geleneksel imgelerden oluşan ve bir birine manevi duygularla bağlanan üçgenden birinin kopması diğer ikisinin de kaderini etkiler. Bu zincirde en büyük sorumluluğu insan gibi canlı varlığın üstlenmesi gerektiğini Flus Latıyfi de vurgulamıştır. Kendi topraklarından ve geleneklerinden kopan, milli değerlerin gücüne inanmayan yeni kuşak için bir ibret olsun diye yazılan hüzün dolu bu hikâyeler, geçmişteki kültürel yaşam tarzımızın bir hafızası niteliğindedir. Somut değerleri kendinde muhafaza eden sandıklar ve sandıkları oluşturan anneler ve nineler, kuşaklar arasındaki bağlantıyı korumaya ve geleceğe aktarmaya çalışan önemli bir köprü vazifesindedir.

Çağdaş Başkurt edebiyatı yazarı Aida Hayrutdinova'nın milli değerleri ele alan "Kaderin dersi" isimli hikâyesinde de konuya insan odaklı yaklaşılır. Geriye dönüş tekniğiyle yazar, "dürüstlükten asla taviz vermeyen, yalan söylemeyen, hiç kimsenin karşısında da küçük düşmeyen" Helime bacının zor dönemlere denk gelen geçmişini kısaca canlandırır. Eserde tanıdık imajlarla karşılaşırız: Seksen yaşındaki Helime bacı ve onun en değerli eşyalarından sayılan sandığı ve sandıkta korunan sulpıları. "Çulpılar," tüm etnik gruplarda kullanılan süs eşyasıdır. Saçın uçlarına takılan çulpı pullarından yürürken güzel sesler çıkar. 0 sadece süs eşyası da değildir, aynı zamanda muska yani kadınları kötü ruhlardan, cinlerden ve nazardan koruma muskası da (Tatar Tĕlĕnĕy, 2016: 230) olduğu bilinir.

Hikâyede sulpıların manevi değeri yetiştiği kültürün münferidi olan kadınların kaderi üzerinden anlatılır. Eskiden sulpılar yani altın, gümüş vb. pullarla yapılan saç örgüsü süsü, özellikle Tatar ve Başkurt kültüründe kızlar için daha çok önem taşırdı. Hayatının sonu geldiği anlayan Helime bacı, gençliğinin hatırası olan sulpılarını kendisine pınardan su getiren Hılıu'ya sandığından özenle çıkarıp verir. "Bu gümüş sulpılar benden sana hatıra olsun. En sevdiğim kız sensin. İște geldim, iște gidiyorum, günüm doldu benim, saatimi bekliyorum", der Helime bacı kendi hayatı üzerinden bu yaşamda hiçbir şeyin ebedi olmadığını göz önünde tutarak. Yaşlılıkta en özlenen dönem, gençlik, güzel umutlarla dolu gençlik yıllarıdır. Ana kahramanın hatıralarına göre, Başkurt kızları gençken saçlarına güzel sulpılar takarak, pınar başına su almaya gelirler, köy gençleri hakkında konuşurlar ve suya bakarak dilekte bulunurlarmıș. Bu olaya bağlı olarak yazar Başkurtların bir geleneği hakkında da bilgi verir: "Aklında olsun kızım", dedi. Benim hatam, benim kaderim ders olsun sana. Evlenmeden önce su doldururken dilek tutarsan o dilek gerçekleşiyor. Pek doğru, tecrübe edilmiş sözler bunlar yavrum. Pınara her gittiğinde söylediklerimi hatırla..." diye tamamlar sözlerini (Hayrutdinova, 2016:313).

Hikâyedeki kısa parçalardan ve ana kahramanın hatıralarından Helime bacının mutsuz bir hayat geçirdiği anlaşılır. Gençlik yıllarının ve

* Başkurtlarda ç sesinin s sesine dönüşmesinden dolayı Tatarca "çulpı", Başkurtca "sulpı", denir. 
mutluluğun nedeni bugün onun için sandıkta saklanan sulpılarda gizlenir. Hayatta mutlu olmak için gençlikte yerine getirilen inanışlar (örneğin; su alırken dilekte bulunmak), gençliğin hatırası olan sulpılar, sulpıları koruyan sandık ve bunları gönül dünyasında yaşatan Helime bacı, ayrı bir kültürün ve ayrı bir dönemin canlı şahitleridir. "Gümüş Bilezik" hikâyesinde anlatılan Cihan teyzenin sandığında bulunan bilezik, dünyada nasıl yaşayacağını açıklayan nasıl bir tılsımlı eşya ise, Helime bacının sandığında bulunan sulpılar da hayatta mutlu olabilmenin sırını kendinde taşır. Böyle değerli yadigârları ve hatıraları koruma sorumluluğu sandıklara yüklenir.

Sovyet döneminin ünlü Başkurt yazarlarından Zeynep Biysiva'nın (1908-1996) "Hönerse ve Öyrensek" (Usta ve Çırak) hikâyesinde de sandık, önemli fonksiyonuna sadık kalarak, kendisinde geçmişi muhafaza eden bir nesne olarak görev yapar. Fakat sandık içinde bulunan eşyalar üzerinden geçmişteki bazı anıları betimlerken, gurur duygusu içeren pozitif ruh ağırlık kazanır. Sandık bu eserde Başkurt Türklerinin şanlı geçmişinde yer edinen önemli tarihi olayların ve tarihi şahsiyetlerin hatırası olan nesneleri koruyan ve canlı tarihi yaşatan bir mekân olarak sunulur. "Köșe kenarlarını sıçan kemirip, tahtalarını kurt yiyip delik deşik etmiş, paslanmış teneke kaplamalı büyük ahşap sandık" ile parlak ve mülayim yüzlü, çoktan yetmişi geçmiş Hasbulat amca, hikâyenin ana kahramanları olarak, bir birini tamamlayan, ikisi bir bütün olan ve ikisi de aynı görevi üstlenen varlıklardır. Hikâye, anlatıcı ile Hasbulat amcanın karşılıklı konuşması üzerine kurulur ve amcanın iç dünyası ve duyguları kendi ifadeleriyle veya ses tonu, konuşma tarzı, yüz ve el hareketleri aracılığıyla açılır.

"Yedi nesilden beri elden ele geçip gelen bir sandıktır bu. Ata babalardan kalan yadigâr..." (Biyișeva, 2001: 346), diyerek, Hasbulat amca sandığın kilidini açıp, onun içinden değerli yadigârları birer birer çıkararak anlatıcının önüne dizmeye başlar. Yazar, sandıkta bulunan yadigârları tanıtırken, onların dış görüntü tasvirine çok önem verir, diğer taraftan ait oldukları şahıslar hakkında bilgilendirir. "İlk önce masaya yılların geçmişiyle sararıp parlayarak kemik rengine girmiş fantastik sürüngen hayvanın başına benzetilerek yapılan kollu ahşap kulp yer aldı. Onun ardından boynuzdan yapılmış borazan göründü. Salavat bahadır, kendi askerlerini savaşa çağırırken bu borazanı çalarmış, diye anlatıyor Hasbulat amca. - Bizim neslin en yaşlı aksakalı Samat, Salavat'ın borazan çaları olmuş. İște o Samat'tan kalan yadigârdır bu...

Bu defa sandıktan gümüş koşumlu, gümüş süslemeli büyük eyer çıkardı. Eyerin ardından, aynı șekilde, gümüşten, gerçek akiklerle bezenerek işlenmiş kayıș dizgin, semer, koşum, sonra kınına aslan ve güvercin kafası resmi işlenmiş ağır geniş kılıcı masaya koydu.

- Bilmek istersen, bu kılıcın sahibi aslan gibi cesur yürekli, gök güvercin gibi saf, iyi gönüllü insan demektir bu, - diye anlatmaya başladı.Sahibi ise kimdir, diyorsunuz? Önder Kahım. Kılıç da, semer ile dizginler de Önder Kahım'a ait. 0, bizim yörenin bahadırıdır. Napolyon'u dövüp Paris'i 
kuşatarak şehre girerken onun elinde bu bulat (çelik) kılıç varmış. 0 bulat kılıcın ise Ural çeliğinden bizim demirci erkeklerimiz yapmıș." (Biyişeva, 2005: 347).

Başkurt halkının 18 yy. ve 19 yy. döneminin milli kahramanları Salavat Yulay ve Önder Kahım ile özdeşleştirilen ve daha çok çeşitli hayvanlara ve kuşlara benzetilerek yapılan değerli eşyalar, aynı zamanda Başkurt Türklerinin doğanın gücüne olan inancının ve sanata verilen değerinin de göstergesidir. Sandıkta Sovyet döneminin hatıraları da bulunur, amca bunları övgü ve özlemle anar. Mesela; paslanmaya yüz tutmuş "Kızıl Yıldız"lı papaha (Kafkasların giydiği koyun yününden yapılmış bir çeşit şapka), fotoğraf, Sovyetler tarafında savaşta gösterdiği kahramanlıklarından dolayı ödüllendirilen "Georgiy" ve "Kızıl Bayrak" madalyaları, tarihin canlı şahidi Hasbulat amcanın kendisine ait, Kızıl Ordulu askerlik çağından kalan yadigârlardır.

İnsan bir dönemin ve kültürün ürünü olduğu gibi, bir tane değerli eşya da pek çok zaman bir dönemi ve bir kültürü yansıtabilir. Onlardan Başkurtların eskiden yaylada yaşarken kımız koyup atın eyerine bağlayarak taşıdığı deri mahfaza kaplarından "botsa", "kulsa", "turhık-mahfaza" gibi eşyalar da sandıkta bulunur. Sandığın en dibinden eski kırmızı kadife kumaşa sarılı tomarın içinde kuğu boyunlu, acayip güzel bir testi de büyük anlam taşır, zira o, "Dağ kızlarının su taşıdığı bir testidir". Yazarın da vurguladığına göre, bu sıradan bir testi değil, büyük bir sanat eseri, orada insan hayali ve elinin yarattığı tekrarlanmayacak bir icat bulunuyordu.

Geçmiş kültürü koruyarak, günümüzdeki yozlaşmaya karşı durabilme konusunu ele alan ve bu süreçte sandık imajına önemli anlam yükleyen Çağdaş Tatar ve Başkurt hikâyelerinde pek çok ortak özellik göze çarpar. Eskimiş, yıpranmış sandıklar her yaşlı için geçmiş dönemin yeni zaman koşullarında da devam edebilmesine destek olan en değerli eşyadır. "Usta ve Çırak" hikâyesi hariç, yazarlar kültürü ve milli değerleri koruyan ve gelecek kuşağa aktaranlar olarak nineleri görür, onları Milletin Anası olarak simge seviyesinde tasvir eder. Gençliği, ayrı bir dönemi ve yaşam biçimini kendisine sindiren değerli ve tılsımlı yadigârların yeni kuşakta anlam taşımaması, eserlerin betimlemesinde hüzün duygusunun ağırlık almasına neden olur. Hikâyelerin kahraman kadrosunu "bir tarafta değişime ayak uyduramayarak kendi değerlerini yetiren genç nesil, diğer tarafta her yandan geçmişine ve geleneklerine sıkı sıkıya bağlı" (Azap, 2016: 315) yaşlı nesil oluşturur.

Sonuç olarak, Çağdaş Tatar ve Başkurt Türklerinin edebi eserlerinde sandık, milli kültür öğelerini taşıyan sözcük, belli bir kültürün kodu olarak sunulur. Sanatçıyı sandığın biçiminden ziyade, onun koruyucu özellikleri, milli kültürün izlerini yansıtan içeriği ilgilendirir. Bu yolda halkın düşünce ve davranış tarzını sözde yansıtan imgeleri fonksiyonel yönden ele almak farklı değişik sonuçlara yol açar. Milli kimlik meselesi üzerinde çalışmaların yoğunlaştığı dönemde, halk kültürünü yansıtan bu tür eserler kültürbilim ve 
dilbilimin bir araya geldiği kültürdilbilim açısından incelemeler için de zengin kaynak olur.

\section{Yazlh Kaynaklar}

\section{KAYNAKÇA}

BIYIȘEVA,Zeynep (2005). “Usta veÇırak”, Türkiye Dışındaki Türk Edebiyatları Antolojisi, 30 Cilt. Başkurt Edebiyatı, s. 346-359, Ankara : T.C. Kültür Bakanlığı Yayınları.

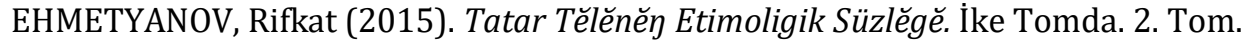
Kazan:Megarif-Vakıt Neşriyatı.

HAYRETDINOVA, Aida (2016). "Kaderin Dersi", (Hzl.: Orhan Söylemez - Samet Azap), Türk Dünyası Edebiyatları, Hikâye Çözümlemeleri, s. 309-314, İstanbul: Kesit Yayınları.

KAMALIEEVA, Alsu (2013). "Emirhan Yeniki'nin "Bir Saatliğine" Hikâyesi ve Tatar Edebiyatinda Savaşin İzleri", Turkish Studies International Periodical For The Languages, Literature and History of Turkish or Turkic, Volume8/1, s. 1781-1792.

LATIYFI, Flüs (2001), “Gümüş Bilezik”, Türkiye Dışındaki Türk Edebiyatları Antolojisi, 19 Cilt. Tatar Edebiyatı, s. 409-419, Ankara: T.C. Kültür Bakanlığı Yayınları.

Milliyĕt Süzlĕgĕ (2007). (Tözüçe-Avtor Adlĕr Timĕrgalin), Kazan: Megarif Yayınları. SÖYLEMEZ, Orhan - AZAP, Samet (2016). Türk Dünyası Edebiyatları-Hikâye Çözümlemeleri. İstanbul: Kesit Yayınları.

Tatar Tĕlěnĕy Etnomedeniyĕt Süzlěgĕ: Maddi Medeniyĕt Lĕksikası (2016). (TözüçeAvtorlar: R.R.Camalĕtdinov hb). Kazan: Kazan Univĕrsitětı Neşriyatı.

URMANÇĕ, Fatih (2009). Tatar Mifologiyesĕ. Ĕnsiklopĕdik Süzlĕk: 3 Tomda. 2.Tom. Kazan: Megarif Neşriyat.

YENİKI, Emirhan (2012). Vasiyet /Vasiyet, (Çev.: Fatih Kutlu, Hamza Ersoy, Nadir T. Arslan), s. 54-101, İstanbul: Zambak Yayınları,

ZARIPPOVA ÇETIN, Çulpan (2016). Alimcan İbrahimov'un Eserlerinde Tatar, Başkurt ve Kazak Türklerinin Kültürel Değerleri. Ankara: Bengü Yayınları.

ZARİPOVA ÇETIN, Çulpan (2009). Tatar Türklerinin Gelenek ve Görenekleri. Ankara: Karadeniz Dergisi Yayınları.

ZARİPOVA ÇETIN, Çulpan (2019). "XX. Yüzyıl Kazan Tatar Edebiyatı”, Türk Dünyası Çağdaş Edebiyatları El Kitabı, s. 569-813, İstanbul: Kesit Yayınları.

Sözlü Kaynak: Zakirova, İlsěyĕr, Kazan, 1968, Tataristan İlimler Akademisi, Dil, Edebiyat ve Sanat Enstitüsü Halk Edebiyatı Uzmanı. (Görüşme: 15.06.2019)

\section{Elektronik Kaynaklar}

URL-1: https://shansky.lexicography.online

URL-2: https://autogear.ru/.../skazochnyiy-derevyannyiy-sunduk

URL-1: Сказочный деревянный сундук https://autogear.ru/.../skazochnyiyderevyannyiy-sunduk/ (Erişim: 22.05.2019) 